\title{
A Conceptual Study of Key Barriers in Construction Project Coordination
}

\author{
Tey Kim Hai ${ }^{1}$, Aminah Md Yusof ${ }^{1}$, Syuhaida Ismail ${ }^{2}$ and Lee Foo Wei ${ }^{3}$ \\ ${ }^{1}$ Faculty of Civil Engineering, University of Technology Malaysia, Malaysia \\ ${ }^{2}$ University of Techology Malaysia International Campus, Malaysia \\ ${ }^{3}$ Faculty of Engineering, University of Malaya, Malaysia
}

\begin{abstract}
The complexity of the nature of construction makes it one of the most adverse businesses that has ever existed. Construction projects have often suffered from high fragmentation, large waste, poor productivity, cost and time overruns, and conflicts and disputes for a long time. Thus, many new and innovative management and procurement systems in construction are introduced such as partnering, joint venture, alliances, supply chain management, enterprise resource planning (ERP), just in time (JIT), and total quality management (TQM) to meet these challenges. However, these construction management and procurement systems are meaningless without coordination, a vital managerial principle and activity, which provides the best cooperation among team members. Although coordination plays crucial functions throughout the building process especially during the design and construction stages, some failures in construction projects adopting coordination principles are still observed. Hence, a study is carried out to investigate the key barriers of coordination in construction project. Through the literature review, five groups of key barriers are established in this paper, including the nature of construction, traditional contractual arrangement, construction participants, characteristic of organization and construction management approach. The investigation of these key barriers is expected to assist the construction players in coordinating their projects towards a better implementation of the innovative management and procurement systems. Lastly, worthwhile new research topics are suggested by this paper in developing the coordination key performance indicator (KPI) and critical success factor on construction project for further studies.
\end{abstract}

Keywords: Key barriers, coordination, construction.

\section{Introduction}

Construction industry covers a wide range of projects and every construction project is unique in nature as it involves myriads of interrelated activities, tasks and work packages (Chris, 2009). With these complexities, construction is observed as the most adverse business among many industries. Therefore, construction projects have commonly suffered from high fragmentation, large waste, poor productivity, cost and time overruns as well as enduring conflicts and disputes (Xue et al, 2005).

Copyright (C) 2012 Tey Kim Hai, Aminah Md Yusof, Syuhaida Ismail and Lee Foo Wei. This is an open access article distributed under the Creative Commons Attribution License unported 3.0, which permits unrestricted use, distribution, and reproduction in any medium, provided that original work is properly cited. Contact author: Tey Kim Hai E-mail: khtey2@live.utm.my 
In a rapidly changing business industry, construction industry needs to be adaptable to new environments to maintain its competitiveness and core business as well as to improve its performance (Chang and Shen, 2009). In line with this streamlining effort, many scholars have studied several innovative management and procurement systems in construction industry including partnering, joint venture, alliances, supply chain management, enterprise resource planning (ERP), just in time (JIT) and total quality management (TQM) (Whyte and Lobo, 2010).

However, most of these management strategies have been originated and developed solely from other industries, especially manufacturing industry. Thus, adopting these concepts into the construction industry is something new and is considered challenging due to the nature of the construction industry especially the fragmentation embedded throughout its processes. In an effort to comprehensively reform the traditional business process, construction industry must strengthen its collaboration, integration, communication and coordination throughout the process, thereby improving the effectiveness and efficiency of its operation (Xue, 2006; Kubicki et al, 2007; Adedeji, 2008; Hassoin, 2009). Hence, coordination should be developed and managed in construction with its intention to ensure project success.

Nevertheless, construction is still in its infancy level of coordination and integration level (CII, 1987). Thus, a question emerged in line with this intention is: what are the key barriers in employing coordination in construction? Therefore, a study related to key barriers of coordination in construction must be carried out so that the real phenomenon of "reluctant to change" related to coordination in construction project can be deeply assessed and developed.

\section{Coordination Concepts and Philosophies}

In thoroughly understanding the barrier, it is necessary to comprehensively understand the coordination in early stage and thus will be discussed entirely in this section. Coordination philosophy is introduced in 1916. In pioneering the work of management principles, Fayol (1949) claims that coordination plays a significant role in managerial activity. This study also points out that coordination provides the best cooperation among team members, thereby improving the communication, integration and team working. The initial findings by Fayol (1949) have attracted many scholars and researches to thoroughly investigate the concepts of coordination. The concepts may be different from each other depending on how coordination is perceived by research scholars in their empirical studies. The study by Alter and Hage (1993) defines coordination as a mode of control, which has been fundamentally underpinned by organizational design principles. In this context, coordination must exist in any organization structure and it plays crucial roles in managing the interfaces in an organization.

Malone and Crowston (1994) argue that coordination theories are the focus on studying the interdependence between activities. Chang and Shen (2009) have the same opinion and define coordination as an approach of managing business by cooperating the interdependence in more than one task, people or organizational unit. Both studies are explicitly recognizing the significance of coordination in managing dependent linking. In complex interdependence, close coordination is critical in ensuring project performance, especially finish-to-start linking. For instances, successive activity depends on predecessive activity, and obstruction of predecessive activity directly affects the start date of successive activity. 
Some researchers have studied the coordination as an induction of excellent relationships in the working environment. The study by Van de Ven (1976) has stated that coordination is the mode of linking together different parts of an organization to perform a set of collective tasks. Xue (2006) has the same opinion that coordination between organizations is the operation of their relationships. These studies typically describe that relationship of personnel and activities can also be improved through the coordination. This claim is supported by Carriero and Gelernter (1990) who observe coordination as the process of building programs by gluing together active pieces. In this context, coordination is a necessity in ensuring the improved relationships of project member, tasks, and activities in terms of cooperation, integration and collaboration working environments.

In some cases, coordination is discussed in information exchange context. Gelernter and Carriero (1992) claim that coordination is the involvement of information exchange among active agents. Malone (1988) also defines coordination as the additional information processing, which is performed when multiple and connected actors pursue goals, a single actor pursuing the same goals would not appear. It shows that coordination plays crucial roles in information sharing in pursuing the participants are in one direction to prevent conflicts of information. Eventually, it improves the quality of information and reduces duplicate information exchange, which ultimately wastes time and money.

On the other hand, Wong (2004) observes coordination as different parts of an organization in supply chain to achieve mutual benefits. Higgin and Jessop (1965) have the same opinion that coordination functions to manage the different activities and intense supervision towards a common purpose. Chitkara (1998) also agrees that coordination aims at an effective harmonization of the planned efforts for accomplishing goals. This claim is also supported by Singh (1992) who depicts that the integration and harmonious adjustment of individual work efforts towards the accomplishment of a larger goal is essential. In these contexts, it is pointed out that the coordination will provide a win-win benefit among participants. When the participants are willing to corporate, work together, share information and learn, their efforts will eventually enhance the performance.

These discussions describe the main concern and principle of coordination that focus on organization, interdependency linking, relationships, information exchange and common goals among team members in various industries. Several questions emerge in line with this intention. What is the coordination context solely adopted in the construction industry? How does the characteristic of construction respond to coordination approach? In comprehensively identifying these answers, coordination in construction industry must be closely examined, and thus will be discussed in the next section.

\section{Coordination in Construction}

Concepts and philosophies of coordination are varied based on different study objectives. Nevertheless, it must be ensured that coordination can be implemented in many kinds of sectors such as manufacturing, logistics, services as well as the construction sector. In deeply understanding the sole scenario of construction coordination, coordination philosophy, which is interpreted into the construction management practices, must be explored in detail. However, a list of questions initially arises in line with how effective and efficient coordination is adopted in the hostile nature and characteristic of construction. Thus, this section has been materalised to pinpoint the characteristic and nature of construction in response to the coordination environment and coordination principles adopted in the construction industry. 
According to Xue et al (2007), process of construction starts from demands by the client, conceptual, design and construction to maintenance, replacement and eventual decommission of building (Xue et al, 2007). The complex process in construction project consists in a myriad of activities, so it necessitates the large numbers of participants who have different characters to carry out the specific task to complete the project goal (Hanrot, 2003). In this effort, coordination between participants always faces challenges in construction (Kubicki et al, 2006). Hence, the ideal coordination environments have rarely existed in construction industry, yet, they have increased the frequency of litigation and disputes. The issues behind these problems have attracted some researchers to focus on studies of coordination in construction processes. The study by Kubicki et al (2007), states that coordination is a vital activity during the building construction process. In this context, coordination and cooperation among members are a prerequisite to build up effective and efficient processes of construction. Kubicki et al (2007) have further modeled a building construction dashboard and cooperative platform for collaboration tools for coordination in construction processes. This model-based tool has assisted the informal and implicit coordination, which allows participants to navigate through the contextual information of the project, therefore improving the collaborative processes in construction.

In some cases, coordination in construction has been examined with regards to the contractual arrangement of project. Traditionally, contractual relationships among construction participants have been seen as adversarial due to the continuous use of fragmentation procurement system. Fragmentation of traditional procurement practice has distinguished the process of working between design and construction, thereby evaporating the relationships of parties involved (Baiden et al, 2006). Kubicki et al (2007) claim that the success of construction project is characterized by relations between participants. Pocock et al $(1996,1997)$ have the same opinion that a sufficient level of interaction between designers and constructors brings success to the overall project performance. Hence, coordination is more needed for such environment to build up teamwork and integration working environment, and it is fundamentally necessary for ensuring the success of a construction project. This claim is supported by Higgin and Jessop (1965) who identify coordination as crucial functions which discuss the building process, especially during the design and construction phase. In this context, coordination is essential to improve the separate working environment through interaction and integration of the design and construction stages. At the same time, coordination reduces the error and discrepancy throughout the overall process, thereby mitigating the likely time delays and incurred cost of rework. Lyer and Jha (2005) agree that coordination between project participants is the most significant factor with the greatest impact on cost performance. Accordingly, lack of coordination may cause duplicity of work and thus results in wasteful expenditures.

Some researchers studied the coordination context under the focus of the changing nature of temporary construction project. Average time frame of construction project is short and the limited time frame has built up a temporary organization. It leads to the frequent changing of its resources, especially to the participants involved. Chris (2009) claims that the changing of the construction workforces has brought the impact of less opportunity for them to develop long-term working relationships and team working; thereby increasing the barrier for them to efficiently function in a working process. Chitkara (1998) has the same opinion and points out that the nature of the changing situations of construction is a necessity in incorporating the coordination principles in the various departments. In these contexts, coordination may facilitate the information exchange, chain of command and 
communication in the construction process, and therefore it improves the integration and interaction of construction's participants.

On the other hand, construction organization structure is developed based on the project. In this organization, team members consist of varying function roles and other interlinked roles. Thus, it requires a high level of cooperation and coordination among project team throughout the construction processes (Adedeji, 2008), so that a higher degree of operational efficiency can be achieved for a project (Hassoin, 2009). Soh and Wang (2000) concur that a high level of coordination is a prerequisite among all the project teams, from office to the construction site until the project is completed. Nevertheless, the level of coordination in construction project is found to be difficult to assess. Therefore, the study by Saram (2002) suggests that a formal understanding of how day-to-day coordination on a construction project is a need to provide a better understanding of level coordination in project. This study has identified the total of 64 coordination activities by the project coordinator in order to achieve day-by-day coordination, and these have been ranked in accordance with its relative importance. However, this paper only focuses on common features underlying the different coordination activities in construction project. In thoroughly understanding, Jha and Misra (2007) further develop the findings of Saram and Ahmed (2001) in considering the impact of coordination activities on project outcome. Jha and Misra (2007) notice that coordination contributes to the outcome of the project, and therefore it is a necessity and is empowered to get a better understanding of the overall importance of an activity. Accordingly, a total of 59 coordination activities has been identified and ranked based on the four performance criteria (schedule, cost, quality and no-dispute) for the relative importance of these activities. In this context, critical coordination activities have strong influences to coordination performance and project outcome, thus they must be given due attention and concern, instead of handling all the activities simultaneously. Hence, the coordinator has a sufficient attention and will be able to spend scarce time in managing the coordination in construction project, which is essential in attaining the desired performance level.

Although previous authors discussed various themes of coordination, they fail to comprehensively identify the key barriers of implementing coordination in the construction industry. Therefore, a study must be carried out to investigate the key barriers of coordination in construction project so that coordination can be meticulously improved and developed.

\section{Key Barriers of Construction Project Coordination}

As the concepts and principles of coordination have been vastly dug out, this section provides a framework for a better understanding of key barriers of coordination in construction project. According to Hassoin (2009), coordination is an abstract concept that is difficult to be measured quantitatively. Coordination is measured by using a combination of other factors such as attributes and the key barriers of coordination. Thus, this section provides a holistic understanding of key barriers of coordination and these apparently can be the criteria of coordination performance indicators for further studies. In this paper, key barriers of coordination in construction are discussed in a different context and categorised into a specific group for better understanding. Five groups of key barriers are established in this paper, including the nature of construction, traditional contractual arrangement, construction participants, characteristic of organization and construction management approach. These groups of key barriers are therefore further elaborated in the succeeding five sub-sections and shown in Diagram 1. 


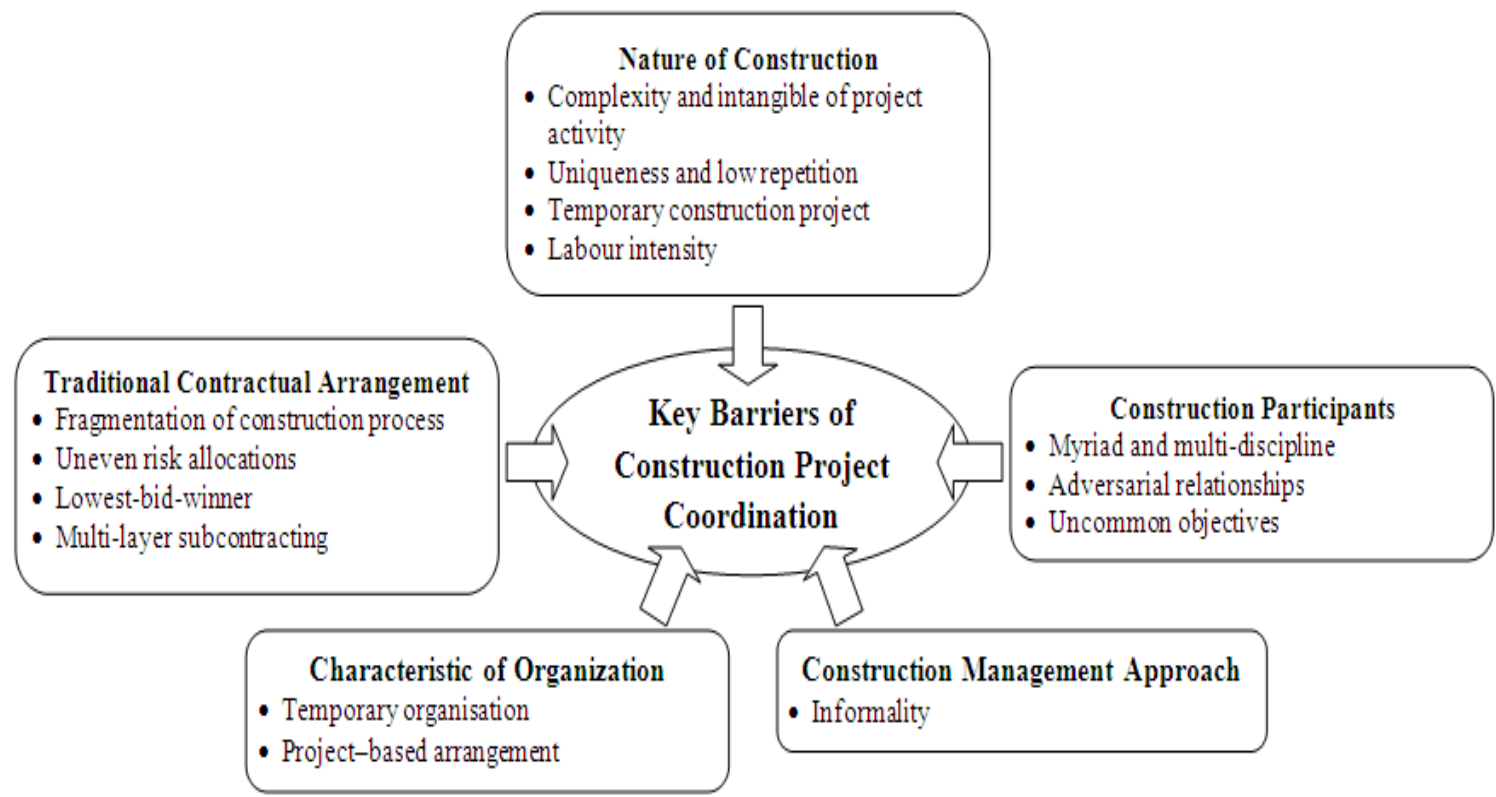

Diagram 1. Key Barriers of Construction Project Coordination

\section{Nature of Construction}

Nature of construction has been widely criticised by many researchers including Latham (1994) and Egan (1998). Based on the nature of construction, complex and intangible project activity, uniqueness and low repetition, temporary construction project and labour intensity are observed as the barriers have led to high level of coordination failures. Thus, there are four key barriers under the nature of construction identified in this paper and are discussed thoroughly in the following sub sections.

\section{Complexity and Intangibility of Project Activity}

According to Chris (2009), construction project involves myriads of interrelated activities, tasks and work packages. One construction project may possibly make up to thousand of activities (Saram et al, 2009), from substructure work to the external work. Every single activity requires the input of participants who have different and sole roles as well as technical expertise. With these complexities, construction has repeatedly distinguished the process of working and involving numerous and heterogeneous participants (Kubicki et al, 2006). The fragmentation and nonintegration of the construction process increase the adversarial relationships among participants. They lack attention to explore other works, they are unwilling to cooperate, and they have been embedded with selfish objectives and blame culture of time delays of their tasks. Thereby, this key barrier is observed as one of the main causes of poor coordination problems in construction.

\section{Uniqueness and Low Repetition}

According to Jeff (1994), construction not only covers wide ranges of end products but varies from one project to another. The uniqueness of construction characterized by its non-repetitive activities, such as design, process, procurement, participants, location, method and techniques (Kubicki et al, 2007). Unlike construction, manufacturing is a high degree of repetitive operation, high level of standardization, permanent and stable workforces as well as permanent location. These features have shown that working 
processes in manufacturing are tightly integrated and ordered. Adversely, construction participants face a difficulty to define the routine and repetitive processes, as well as input and output in construction project. In such varying processes, project personnel find it difficult to discern the longterm relationships and objectives, which may emerge in previous cooperated project. They are trying to identify customers' and stakeholders' expectations (Saram et al, 2009) and cause the poor communication and fail to understand correctly, eventually leading to poor quality of construction end products. This situation is further complicated by the fact that most project participants carry out their function roles in purpose only in low repetitive nature of the working process (Saram et al, 2009). The reluctance of learning the new skills led to no skills development, whilst they are found difficulty in every new project. Hence, more efforts of coordination should be urged to motivate and initiate the new learning curve for new personnel of a construction project. From the above discussion, it is concluded that this key barrier is the crucial factors that make managing coordination processes more difficult.

\section{Temporary Construction Project}

Average time frame of construction project lasts merely in few years in different geographic locations. The temporary nature of the construction project requires new resources such as new participants, materials, technologies and working methods to achieve the "new born" project. The complexity can make it extremely difficult for new project participants to coordinate disparate parties who may never have worked together before (Saram, 2002). According to Stephen and Christopher (2007), construction individuals and organizations have to be creative and ready in cooperating and coordinating through varying conditions. However, this ideal coordination has rarely existed among construction project participants. It is even worse that participants are reluctant to share information and their technical knowledge because they believe that the temporary time frame of construction projects often impede the establishment of trust (Cheng et al, 2010). Thus, it is observed that this key barrier with lack of commitment for sharing and communication has lead to a high level of poor coordination in terms of conflict and disputes.

\section{Labour Intensity}

According to Geneva (2001), there were an excess of 111 million construction workers worldwide in 1998, most of them were in the low-and middle-income countries. These countries of the world show only 23 per cent of global construction output but have 74 per cent of the total employment. It can be inferred from the above that the "labour intensity" of construction life is not uncommon, especially in the low-income countries. At the same time, construction sector also contributes to the high employment if compared to other sector, namely manufacturing. In manufacturing industry, labour intensity is instead of high degree of industrialization to perform the manufacturing activity. Industrialization has adopted the technological innovation to produce the end product in a more efficient, cheaper way and in mass production. Nevertheless, only the characteristic of high repetitiveness of procedures, process and production in manufacturing are appropriate to industrialization. In comparison with manufacturing industry, uniqueness and low repetition have aggravated industrialization in the construction industry. Up to now, a large number of labours or labour intensity is required in construction project rather than the adoption of automation and technology innovation. A torrent of labours involved, uncontrollable management and poor communication take place between management and personnel. Chain of command from top to bottom management and personnel may also take time and experience to detect information errors during the exchange, and eventually this key 
barrier causes the challenges of coordination labours.

\section{Traditional Contractual Arrangement}

In general, design-bid-build is recognized as traditional contracting system and it is the most common form in delivering the construction project (Greco, 2006; Gehrig, 2009). Design-bid-build is characterized by fragmentation, uneven risk allocation, lowest-bid-price and multi-layer of subcontracting that discourages coordination in a project. These key barriers under traditional contractual arrangement thus will be further developed in the following four sub sections.

\section{Fragmentation of Construction Process}

Traditional contracting approach or designbid-build has been widely applied around the globe (Greco, 2006; Gehrig, 2009). Designbid-build has experienced the three-step processes throughout the design, bid and build phases (Gehrig, 2009). Thus, this contracting approach is awarded apart from different contracts from design professional and contractors (Gehrig, 2009). Due to the rupture in contracts, it distinguishes the design and construction processes, thereby exasperating its process. In this context, the said approach does not promote integration of parties involved in design and construction phases (Baiden et al, 2006). As a result, a lot of problems arise due to design deficiencies during the construction process, such as products that could not be built as designed and could not be efficiently constructed (Rosli, 2004). According to Madelsohn (1997), 75 percent of the problems on the construction site are generated in the design phase. Nevertheless, its origin can be traced back to the adversary nature of traditional contractual arrangement. In the early stage of conceptual design, the contractor is discouraged to provide their technical knowledge and opinion complimenting the design and buildability issues, and thereby resulting in poor communication, little team working, lack of information and knowledge sharing. Therefore, this key barrier has been observed as one of the main factor that contributes to the poor coordination.

\section{Uneven Risk Allocations}

According to Thompson (1995), risks are derived from uncertainty of project activities and thus affect the objectives achievement of the project. Risks obviously exist in the nature of the construction industry and cannot be easily eliminated (Kangari, 1995). Hence, some studies were carried out to investigate the resolution of risks in construction project. Kubicki et al (2006), claim that contractual arrangement plays a pivotal role in risk minimization in construction. This can be explained through the duties and responsibilities of a party depending on individual contractual arrangement (Greco, 2006), which have a significant impact on the risk allocation to project participants. In traditional contracting approach, contracts are separately awarded for the designing professional and contractor (Gehrig, 2009). In this context, although a single point of contact and contact responsibility for all performances during the project does not exist (Anderson et al, 2002), it creates multiple and different roles from different contracts in this contracting system. Due to the uncommon responsibilities by separate contracts, lack of commitment and blame culture appears among participants, which ultimately leads to the challenges of coordination among them (Kubicki et al, 2006).

\section{Lowest-Bid-Winner}

Competitive tendering is the most popular tendering applied in traditional contractual arrangement or design-bid-build (Greco, 2006). In competitive tendering, contractors face two seemingly incompatible and contradictory objectives. They must bid high enough to make a profit, yet low enough to get a job at the same time. However, it is difficult for a contractor to balance between 
both at the same time (Park, 1979). Often, prices were driven down by the competitive pressures (Park, 1979) and usually awarded to the lowest price bidder (Abdul-Hadi, 1999). Therefore, contractors typically focus upon meeting their contractual requirements at the lowest possible price. They may be limited to commitment to achieve the client's primary objectives or to any perceived project team (Pryke, 2009). As a result, they lack willingness to cooperate and coordinate with other participants across construction industry processes, and consequently make the coordination more challenging.

\section{Multi-Layer Subcontracting}

A single main contractor is impossible to control all related project tasks in a construction project. Thus, delivery of construction projects is usually handled by numerous subcontractors with different task packages. In general, larger project will require more than one layer in the subcontracting management. The main contractor not only subcontracts the job to subcontractors, but the first subcontractor may also subcontract this contract to another organization or further subcontract it (Chiang, 2009). Unfortunately, these subcontracting systems often have not been effectively managed (Tam et al, 2011). Hence, lack of adequate control and supervision by main contractors over subcontractors' work and complexity of communication and information flow have led to poor coordination in such subcontracting.

\section{Construction Participants}

The myriad of activities in construction constrains the large number of participants to carry out a task (Hanrot, 2003). They are multi-disciplinary and each has the character of interdependent roles in construction project, thereby rendering it difficult for them in coordination. Unfavourably, adversarial relationships and uncommon objectives among participant aggravate the problems of coordination. Thus, these three key barriers of faultless coordination under construction participants will be discussed thoroughly in the following sub sections.

\section{Myriad and Multi-Discipline}

Construction is based on project organisation and associated myriads of participants such as client, architect, designer and contractor throughout its process. Each player has different roles, technicality and service which contribute to each task in construction. In such complexities, multi-disciplinary of the participants causes a lack of match between the technical interdependence of the work and their organizational independence (Higgin and Jessop, 1965). This can be explained by the limited knowledge and expertise of a participant towards the other works, which are running over their boundaries. Therefore, this results in the adversarial relationship, problematic communication and incomplete information flows, which is eventually perceived as key barrier of close coordination among participants.

\section{Adversarial Relationships}

Construction is a harsh environment due to its narrow, win-lose interest and short-term arrangement of business relationship (Chuah, 2003). In general, ideal relationship among participants is very rare in construction projects. According to Pryke (2009), management of relationships is a core competency in construction, and furthermore, a quality of relationships that is a key element in the success of a project. Hence, effective and harmonious relationship must take place in functioning the cooperation and integration of participants in construction project. Nevertheless, contractual arrangement in construction traditionally does not promote a quality relationship and more intensely leads to adversarial relationships, and ultimately creates poor coordination. 


\section{Uncommon Objectives}

Construction participants were criticized for their uncommon objectives in a similar project. Ankrah and Langford (2005) state that construction participants have different objectives to describe their approaches for work and relationships with other project participants, thereby leading to the conflict at the interface level in one respect. Chuah (2003) also claims that objectives of construction are based on narrow and winlose arrangement. However, the creation of these problems can be traced back to the continuous use of traditional contracting strategy, commitment to which is awarded separately (Gehrig, 2009). In this arrangement, each participant has a certain and sole objective to accomplish the project as stated in the contract. Hence, a common objective has rarely existed in construction. Adversely, selfish objective is apparent in construction, it therefore exasperates the coordination process.

\section{Characteristic of Organization}

According to Stephen and Christopher (2007), the characteristic of the people involved and structure of their organizations are fundamentally crucial in ensuring the coordination during the construction process. Nevertheless, organisational design in construction characterized by being temporary and project-based has exasperated the coordination among them, which are further discussed in the following two sub-sections.

\section{Temporary Organisation}

Stephen and Christopher (2007) claim that the organisation is inevitably stable as its size and culture will change over time. Ad hoc of construction organisation only lasts from 12 to 24 months. In the temporary nature of the organisation, participants have less opportunity to develop long-term working relationships. They are devilishly difficult to build strong communication networks and continually no room for improvement in their work (Stephen and Christopher, 2007). Therefore, it seems impossible to establish a formal coordination in temporary organisation due to shortage of time to communicate and integrate the information flow among different agencies. Due to the constant change of organisation, these problems have led to a difficulty in managing coordination processes in construction.

\section{Project-Based Arrangement}

In construction project, team members such as an architect, designer, contractor and supplier have collaborating together in the project-based organisation structure. Hence, this organisation is dependent on a large number of individuals representing different roles and responsibilities. In such complexities, coordination within their expertise and technical knowledge is a necessity to the success of the project in terms of the lean time of information flow, chain of command and decision making. Nevertheless, the varity of priorities and decision of each participant involved grades the problem in coordination, which eventually leads to duplicity of work, delay in work done and an increase in the project cost (Jha and Lyer, 2007). As a result, the projectbased organisation structure is observed as one of the key barriers of coordination in construction project.

\section{Construction Management Approach}

Management approach predominately contributes to improved competitiveness and core business. However, traditional management system in construction has been carried out informally and leads to difficulty in managing the communication and coordination of construction participants. This claim is supported by Saram et al (2009) who note that management mode in construction has been carried out in informal approach. Crichton (1966) also further claims that the informal management has drawn from direct surveillance at work and confers on the works they were doing. The overall 
processes are not formally documented in handbooks or formal reports of the construction. This results in no previously set methods of obtaining inputs, processing and delivering outputs of vital information in construction (Saram, 2002). This can make it devilishly difficult for participants to communicate without proof or "black and white" documents, thereby leading to high level of conflicts and disputes in a project. Moreover, they are required to establish the new learning curve for every process, as well as the repetitive process. Even so, every process is varying, thus this practice leads to the barriers of effective and efficient coordination among participants.

\section{Summary}

Criticisms of poor performance are not uncommon in the construction industry, and coordination is observed as the best solution to this dilemma. However, construction is still in its infancy level of coordination. The reason behind this phenomenon has attracted the author focus on studies of barriers to employ coordination in construction. Therefore, key barriers of coordination in construction have been investigated by this paper to achieve its objective. A total of five groups of key barriers are observed including the nature of construction, traditional contractual arrangement, construction participant, characteristic of organization and construction management approach. In providing a better understanding, each subgroup is studied thoroughly and summarized by the diagram in this paper. This paper is underpinned by the literature review of theoretical, conceptual and key barriers of construction project coordination. The objectives of the study are successfully achieved by conversation of literature in pioneering the key barriers of coordination in construction project. This study outlines the basic ideas to improve the existing poor performance of construction through emphasizing concerns towards the key barriers of coordination. It is because coordination is observed as a prerequisite to a success of construction project. Once the key barriers are identified, it becomes also easier for future construction participants to develop strategies to tackle these barriers for optimal improvement of the overall project performance. On the long run, it may increase the utmost concern of construction participants in coordinating their project and escalating implementation of the innovative management and procurement systems in the construction industry. This study also initiates a worthwhile new research topic in developing the measurement of coordination performance, which has potential to combine and convert these barriers factors into the key performance indicators (KPI). Thus, it is no longer impossible to assess coordination performance level of construction project in the future. In addition, further study also need to be undertaken to analyse more precisely the effect of coordination on a construction project success through incorporating the coordination into critical success factors of construction, so that reality views of the powerful influences of coordination on a construction project success can materialize.

\section{References}

Abdul-Hadi, N. H. (1999). 'Factors Affecting Bidding and Mark-up Decisions in Saudi Arabia,' Master Degree of Science in Construction Engineering and Management Thesis, King Fahd University of Petroleum \& Minerals, Dhahran, Saudi Arabia.

Adedeji, B. B. (2008). Triple C Model of Project Management: Communication, Cooperation and Coordination, Taylor and Francis Group, London New York.

Alter, C. \& Hage, J. (1993). "Organizations Working Together," Sage Publications, Newbury Park, Calif.

Anderson, D., Baker, J., Burns, B., Catto, C., Douthwaite, D., Eisenberg, L., Foster, B., Johnson, A., Klobertanz, S., Underwood, B. \& Wundram, E. (2002). Design-Build Whitepaper, Oregen Public Contracting 
Journal of Organizational Management Studies 12

Coalition. [Online], [Retrieved August 16, 2011],

http://www.agc-

oregon.org/public/resource_center/publicati ons/db_whitepaper_final.pdf.

Ankrah, N. A. \& Langford, D. A. (2005). "Architects and Contractors: A Comparative Study of Organizational Cultures," Construction Management, 23 (6), 595-607.

Baiden, B. K., Price, A. D. F. \& Dainty, A. R. J. (2006). "The Extent of Team Integration within Construction Projects," International Journal of Project Management, 24 (1), 13-23.

Carriero, N. \& Gelernter, D. (1990). How to Write Parallel Programs, MIT Press. [Online], [Retrieved August 15, 2011], http://www.lindaspaces.com/book/book.pdf

Chang, A. S. \& Shen, F. (2009). "Coordination Needs and Supply of Construction Project," Engineering Management Journal, 21 (4), 4457.

Cheng, J. C. P., Law, K. H., Bjornsson, H., Jones, A. \& Sriram, R. (2010). "A Service Oriented Framework for Construction Supply Chain Integration," Automation in Construction, 19 (2), 245-260.

Chiang, Y. H. (2009). "Subcontracting and Its Ramifications: A Survey of the Building Industry in Hong Kong," International Journal of Project Management, 27 (1), 80-88.

Chitkara, K. K. (1998). Construction Project Management: Planning, Scheduling and Controlling, Tata McGraaw Hill, New Delhi, India.

Chris, M. (2009). Business Organisation for Construction, Taylor and Francis Group, London and New York.

Chuah, C. C. (2003). "Supply Chain Management through Partnering in Malaysian Construction Industry," Master of Science (Construction Management) Thesis,
Universiti Teknologi Malaysia, Skudai, Malaysia.

Construction Industry Institute (CII). (1987). 'Guidelines for Implementing a Constructability Program,' Braker Lane, Austin, Texas, USA.

Crichton, C. (1966). 'Interdependence and Uncertainty: A Study of the Building Industry,' Tavistock Publications Limited, London.

de Saram, D. D. (2002). Measuring the Quality of Contractors' Coordination Activities during the Construction Process,' Doctoral Degree of Civil and Structural Engineering (Management) Thesis, The Hong Kong Polytechnic University, Hong Kong.'

de Saram, D. D. \& Ahmed, S. M. (2001). "Construction Coordination Activities: What Is Important and What Consumes Time," ASCE Journal of Management in Engineering, 17 (4), 202-214.

de Saram, D. D., Ahmed, S. M. \& Anson, M. (2009). "Suitability of the Critical Incident Technique to Measure Quality of Construction Coordination," ASCE Journal of Management in Engineering, 20 (3), 97-109.

Egan, J. (2002). 'Accelerating Change: A Report by the Strategic Forum for Construction,' Rethinking Construction, London.

Egan, S. J. (1998). 'Rethinking Construction: The Report of the Construction Task Force,' HMSO, London.

Emmitt, S. \& Gorse, C. A. (2007). 'Communication in Construction Teams,' Taylor and Francis, London and New York:

Fayol, H. (1949). "General and Industrial Management," Pitman and Sons, London.

Gehrig, D. S. (2009). 'Alternative Project Delivery Methods for Public Work Projects in California,' Hanson Bridgett LLP. [Online], 
[Retrieved August 15, 2011], http://www.hansonbridgett.com/docs/articl es/AltProjectDeliveryMethods_DSGehrig.pdf.

Gelernter, D. \& Carriero, N. (1992)."Coordination Languages and their Significance," Communications of the ACM, 35 (2), 96-107.

Geneva (2001). The Construction Industry in the Twenty-First Century: Its Image, Employment Prospects and Skill Requirements," International Labour Office Geneva, Switzerland. [Online], [Retrieved August 13, 2011], http://www.ilo.org/public/english/standard s/relm/gb/docs/gb283/pdf/tmcitr.pdf

Greco, A. (2006). 'Design-Build and DesignBid-Build in the GTA (Great Toronto Area),' Bachelor Degree of Construction Engineering Technology Management Thesis, George Brown College, Canada.

Hallowell, M. \& Toole, T. M. (2009). "Contemporary Design-Bid-Build Model," Journal of Construction Engineering and Management, 135 (6), 540-550.

Hanrot, S. (2003). 'Enjeux pour l'ingenierie de maitrise d'oeuvre,' Plan, Urbanism Construction Architecture, Practiques de project et ingenieries, Paris.

Hassoin, L. (2009). "Communications and Coordination in Construction Projects," Construction Management and Economics, 27 (1), 25-39.

Higgin, G. \& Jessop, N. (1965). Communications in the Building Industry: The Report of a Pilot Study, Tavistock Publications Limited, London.

Jeff, W. (1994). 'Conflict in Construction Avoiding, Managing, Resolving,' Machillan Press Ltd, London.

Jha, K. N. \& Lyer, K. C. (2007). "Commitment, Coordination, Competence and the Iron
Triangle," International Journal of Project Management, 25 (5), 527-540.

Jha, K. N. \& Misra, S. (2007). "Ranking and Classification of Construction Coordination Activities in Indian Project," Construction Management and Economics, 25 (4), 409-421.

Kangari, R. (1995). "Risk Management Perceptions and Trends of U.S. Construction," Journal of Construction Engineering and Management, 121 (4), 337-475.

Kreps, G. L. (1989). 'Organizational Communication,' Allyn and Bacon, United States of America.

Kubicki, S., Bignon, J. C. \& Halin, G. (2006). "Building Construction Coordination by an Adaptive Representation of the Cooperation Context," Joint International Conference on Computing and Decision Making in Civil and Building Engineering, 14-16 June 2006, Canada, 3324- 3333.

Kubicki, S., Bignon, J. C., Halin, G. \& Humbert, P. (2007). 'Assistance to Building Construction Coordination: Towards a Multiview Cooperative Platform,' Journal of Information Technology in Construction, 11 (2006), 565 - 586.

Latham, M. (1994). 'Construction the Team: Final Report of the Government/ Industry Review of Procurement and Contractual Arrangements in the UK Construction Industry,' HMSO, London.

Lyer, K. C. \& Jha, K. N. (2005). "Factors Affecting Cost Performance: Evidence from Indian Construction Projects," International journal of project management, 23 (4), 283295.

Madelsohn, R. (1997). "The Constructability Review Process: A Contractor's Perspective," ASCE Journal of Management in Engineering, 13 (3), 17-19.

Malone, T. W. (1988). "What is Coordination Theory?" Sloan School of Management 
Working Paper, February 1988, Massachusetts Institute of Technology, Cambridge, 20512088.

Malone, T. W. \& Crowston, K. (1994)."The Interdisciplinary Study of Coordination," ACM Computing Surveys, 26 (1), 87-119.

Park, W. R. (1979) .Construction Bidding for Profit, John Wiley \& Sons. Inc., United States of America.

Patacconi, A. (2009). "Coordination and Delay in Hierarchies," The RAND Journal of Economics, 40 (1), 190-208.

Pocock, J. B., Hyun, C. T., Liu, L. Y. \& Kim, M. K. (1996). "Relationship between Project Interaction and Performance Indicators," Journal of Construction Engineering and Management, 122 (2), 165-176.

Pocock, J. B., Liu, L. Y. \& Kim, M. K. (1997)."Impact of Management Approach on Project Interaction and Performance," Journal of Construction Engineering and Management, 123 (4), 411-418.

Pryke, S. (2009). Construction Supply Chain Management: Concepts and Case Studies, John Wiley \& Sons Ltd and Blackwell publishing Ltd., United Kingdom and United States.

Rosli, M. Z. (2004). 'Constructability Improvement of Project Design,' Doctoral Degree of Engineering Structure and Materials (Construction Management) Thesis, Universiti Teknologi Malaysia, Skudai, Malaysia.

Singh, B. (1992). 'Interconnected Roles (IR): A Coordinated Model,' Technical Report CT84-92, Microelectronics and Computer Technology Crop, Austin, Texas.

Soh, C.- K. \& Wang, Z. (2000). "Parametric Coordinator for Engineering Design," Journal of Computing in Civil Engineering, 14 (4), 233- 241.
Tam, V. W. Y., Shen, L. Y. \& Kong, J. S. Y. (2011). "Impacts of Multi-Layer Chain Subcontracting on Project Management Performance," International Journal of Project Management, 29 (1), 108-116.

Thompson, P. \& Perry, J. G. (1992). Engineering Construction Risks: A Guide to Project Risk Analysis and Ri Management, Thomas Telford, London.

Van de Ven, A. H. (1976). "On the Nature, Formation, and Maintenance of Relations among Organizations," Academy of Management Review, 1 (4), 24-36.

Wang, Y. (2000). "Coordination Issues in Chinese Large Building Projects," ASCE Journal of Management in Engineering, 16 (6), 54-61.

Whyte, J. \& Lobo, S. (2010). "Coordination and Control in Project-Based Work: Digital Objects and Infrastructures for Delivery," Construction Management and Economics, 28 (6), 557-567.

Wong, C. Y., Johansen, J. \& Hvolby, H. H. (2004). 'Supply Chain Coordination Problems: Literature Review,' Working Paper No. 08-04, Center for Industrial Production

Xue, X. (2006). 'Supply Chain Coordination and Its Supporting Platform,' Doctoral Degree in Management Thesis, Hong Kong Technical University, Hong Kong.

Xue, X., Li, X., Shen, Q. \& Wang, Y. (2005). "An Agent-Based Framework for Supply Chain Coordination in Construction," Automation in Construction, 14 (3), 413- 430.

Xue, X., Wang, Y., Shen, Q. \& Yu, X. (2007). "Coordination Mechanisms for Construction Supply Chain Management in the Internet Environment," International Journal of Project Management, 25 (2), 150- 157. 